Jurnal Media

Teknik dan

Sistem Industri

\title{
Aksesibilitas Pelabuhan Kuala Tanjung dalam Mendukung Kelancaran Arus Barang di Kawasan Ekonomi Khusus (KEK) Sei Mangkei, Provinsi Sumatera Utara
}

\author{
Hendy Suryana \\ Teknik Industri Universitas Suryakancana \\ Jalan Pasir Gede Cianjur \\ hendies.free@gmail.com
}

\section{Accessibility of Kuala Tanjung Port in Supporting the Movement of Goods in the Sei Mangkei Special Economic Zone (SEZ), North Sumatera Province}

Dikirimkan: 08, 2020. Diterima: 09, 2020. Dipublikasikan : 09, 2020.

\begin{abstract}
The Sei Mangkei Special Economic Zone (SEZ ), which is located in Bosar Maligas District, Simalungun Regency, North Sumatra Province, with an area of 2,002.77 hectares is stipulated by Government Regulation No. 29 of 2012 in the context of developing new industrial areas directed at industries, based on natural and mineral resources and utilizing strategic geographic location. The success and continuity of the Sei Mangkei SEZ will be determined by the transportation and logistics infrastructure that plays a role in the smooth flow of goods transportation from the Sei Mangkei SEZ to the Port of Tanjung which has a strategic role as a marine transportation logistics hub. The purpose and objective of this study is to analyze the prospects and integration of transportation and logistics facilities and infrastructure at the Kuala Tanjung Port-Sei Mangkei SEZ, in order to realize an integrated transportation and logistics facilities and infrastructure for the development of accessibility of the Kuala Tanjung Port-Sei Mangkei SEZ. Based on the research it is known that port accessibility is increasing, rail and truck modes of transportation can be applied and the need for traffic management and engineering.

Keywords - SEZ Sei Mangkei; accessibility; Kuala Tanjung Port; supply chain system; train; truck.
\end{abstract}

Abstrak- Kawasan Ekonomi Khusus (KEK) Sei Mangkei yang berlokasi di Kecamatan Bosar Maligas,
Kabupaten Simalungun, Propinsi Sumatera Utara, dengan luas 2.002,77 hektar ditetapkan melalui Peraturan
Pemerintah Nomor 29 tahun 2012 dalam rangka pengembangan kawasan-kawasan industri baru yang
diarahkan pada industri-industri berbasis sumber daya alam dan mineral serta memanfaatkan lokasi geografis
yang strategis. Keberhasilan dan kelangsungan KEK Sei Mangkei akan ditentukan oleh infrastruktur
transportasi dan logistik yang berperan dalam kelancaran arus angkutan barang dari KEK Sei Mangkei ke
Pelabuhan Tanjung yang mempunyai peran strategis sebagai logistics hub transportasi laut. Maksud dan tujuan
penelitian ini adalah melakukan analisis tentang prospek dan keterpaduan sarana dan prasarana transportasi
dan logistik di Pelabuhan Kuala Tanjung-KEK Sei Mangkei, guna mewujudkan keterpaduan sarana dan
prasarana transportasi dan logistik untuk pengembangan aksesibilitas Pelabuhan Kuala Tanjung-KEK Sei
Mangkei. Berdasarkan penelitian diketahu bahwa aksesibilitas pelabuhan meningkat, moda angkutan kereta
api dan truk dapat diterapkan serta perlunya manajemen dan rekayasa lalu lintas.
Kata kunci- KEK Sei Mangkei; aksesibilitas; Pelabuhan Kuala Tanjung; sistem rantai pasok; kereta api; truk.

\section{PENDAhuluan}

Kawasan Ekonomi Khusus (KEK) yang telah ditetapkan oleh pemerintah adalah KEK Sei Mangkei, melalui Peraturan Pemerintah Nomor 29 tahun 2012, yang berlokasi di Kecamatan Bosar Maligas, Kabupaten Simalungun, Propinsi Sumatera Utara,dengan luas 2.002,77 Hektar. KEK Sei Mangkei direncanakan terdiri dari tiga zona, yaitu industri, logistik, dan pariwisata. 
Penetapan KEK Sei Mangkei ini sesuai dengan kebijakan pemerintah dalam pengembangan kawasan-kawasan industri baru yang diarahkan pada industri-industri berbasis sumber daya alam dan mineral serta memanfaatkan lokasi geografis yang strategis.

Menurut Direktorat Jenderal Pengembangan Perwilayahan Industri Kementerian Perindustrian, Kawasan Industri Sei Mangkei (KISM) yang merupakan bagian dari KEK Sei Mangkei merupakan bagian dari pengembangan kawasan industri di koridor ekonomi Sumatera [1], seperti yang diperlihatkan pada Gambar 1.

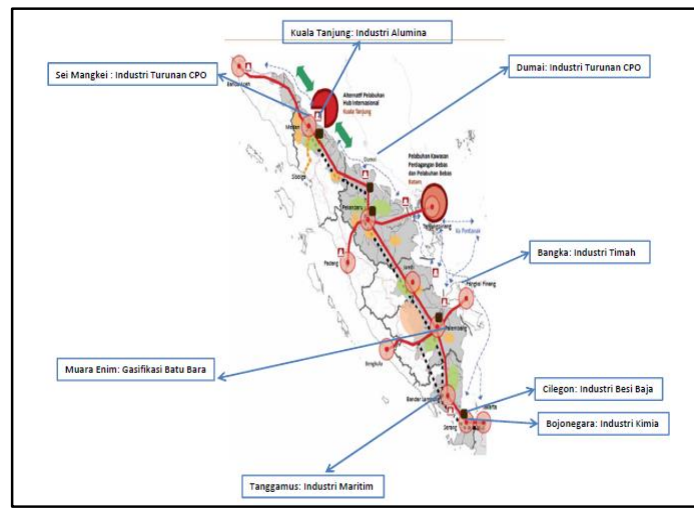

Gambar 1. Pengembangan kawasan industri di koridor ekonomi Sumatera.

Kawasan Industri Sei Mangkei (KISM) berada pada wilayah perkebunan kelapa sawit yang dimiliki oleh PTPN III. Di samping itu, lokasi KISM dekat dengan Pelabuhan Kuala Tanjung milik PT. Pelindo I. Selain itu, sudah ada jalur kereta api dari Gunung Bayu - Stasiun Perlanaan yang jaraknya dekat dengan KISM, sehingga dapat dikoneksikan dengan jalur yang ada saat ini ke Pelabuhan Kuala Tanjung. Gambar 2 memperlihatkan peta jalur kereta api Sei Mangkei - Bandar Tinggi - Kuala Tanjung.

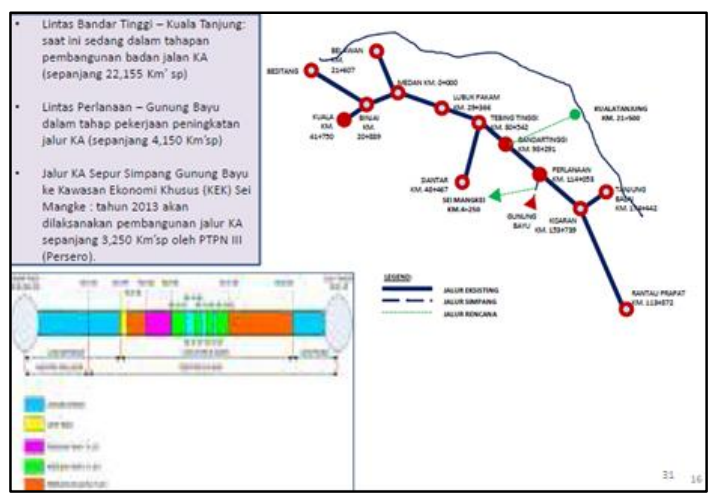

Gambar 2. Peta jalur kereta api Sei Mangkei-Kuala Tanjung.

Potensi penggunaan Pelabuhan Kuala Tanjung akan semakin tinggi dengan keterbatasan yang ada pada Pelabuhan Belawan. Pelabuhan Belawan memiliki kedalaman laut -9,50 mLWS, sedangkan ke depan akan dibutuhkan draft-14,00 mLWS. Berdasarkan Peraturan Presiden tentang Sistem Logistik Nasional, Pelabuhan Kuala Tanjung mempunyai peran strategis sebagai logistics hub transportasi laut. Dengan telah ditetapkannya Kawasan Industri Sei Mangkei sebagai basis industri pengolahan turunan kelapa sawit yang menjadi hinterland Pelabuhan Kuala Tanjung, maka ada potensi angkutan petikemas dan kelapa sawit. Pada masa mendatang, dengan akan beroperasinya KEK Sei Mangkei, maka akan ada penambahan potensi angkutan curah cair dan petikemas. Jika kapasitas Pelabuhan Belawan sudah maksimum, maka angkutannya akan dialihkan melalui Pelabuhan Kuala Tanjung.

Jaringan Transportasi Jalan, merupakan serangkaian simpul dan/atau ruang kegiatan yang dihubungkan oleh ruang lalulintas sehingga membentuk satu kesatuan sistem jaringan untuk keperluan penyelenggaraan lalu lintas dan angkutan. Prasarana transportasi jalan terdiri atas simpul berupa terminal penumpang dan terminal barang dan ruang lalu lintas. Simpul meliputi terminal transportasi jalan, terminal transportasi sungai dan danau, stasiun transportasi KA, pelabuhan penyeberangan, pelabuhan laut, dan bandar udara; sedangkan ruang lalu lintas pada transportasi jalan berupa ruas jalan menurut hirarkiperanannya terdiri atas jalan arteri primer, kolektor primer, dan lokal primer. Pelayanan angkutan dengan kendaraan umum meliputi pelayanan angkutan orang dan/atau barang.

Transportasi diartikan sebagai pengangkutan barang atau orang dari tempat asal kegiatan transportasi ke tempat tujuan dimana kegiatan transportasi diakhiri [2]. Transportasi merupakan bagian integral dari suatu fungsi masyarakat, menunjukkan hubungan yang sangat erat dengan gaya hidup, jangkauan dan lokasi dari kegiatan yang produktif, dan selingan serta barang-barang dan pelayanan yang tersedia untuk dikonsumsi. Jasa transportasi dilakukan karena nilai yang diangkut tersebut akan lebih tinggi ke tempat tujuan [3]. Nilai yang diberikan oleh kegiatan transportasi adalah nilai tempat (place utility) dan nilai waktu (time utility) yang bersifat permintaan turunan (derived demand). Transportasi juga dapat diartikan sebagai usaha memindahkan, menggerakkan, mengangkut atau mengalihkan suatu objek dari suatu tempat ke tempat lain, dimana di tempat lain ini objek tersebut lebih bermanfaat atau dapat berguna untuk tujuan-tujuan lainnya. Karena dalam dua definisi di atas terdapat kata usaha dan proses yang meliputi kegiatan perpindahan, pergerakan, pengangkutan dan 
pengalihan dimana tidak terlepas dari keperluan alat pendukung yang menjamin lancarnya kegiatan tersebut sesuai dengan waktu yang diharapkan. Alat pendukung tersebut berbeda-beda tergantung pada bentuk objek yang akan dipindahkan, jarak antara suatu tempat dengan tempat lain dan maksud objek yang akan dipindahkan sehingga standar kuantitas dan kualitas alat pendukung ini dapat diidentifikasikan melalui indikator-indikator seperti aman, cepat, lancar, nyaman, ekonomis dan terjamin ketersediaannya. Selanjutnya alat pendukung tersebut lazim disebut sebagai sistem transportasi dimana secara keseluruhan, sistem ini terdiri dari sistem kegiatan, sistem jaringan dan sistem pergerakan. Untuk lebih jelasnya, sistem transportasi dapat dilihat pada Gambar 3 berikut.

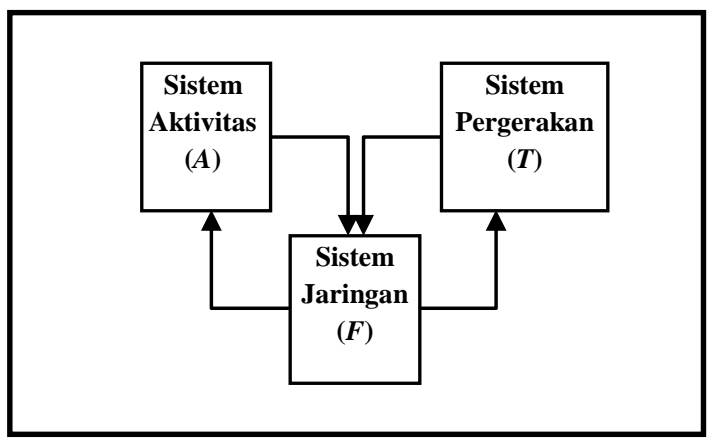

Gambar 3. Sistem transportasi.

Dari gambar diatas dapat dijelaskan bahwa pola jaringan $(\boldsymbol{F})$ sistem pergerakan $(\boldsymbol{T})$ sebagai supply dan sistem aktivitas (A) sebagai demand. Masing-masing sistem tersebut saling berpengaruh walaupun pengaruhnya tidak secara langsung. Hal ini dapat dilihat bahwa tidak ada hubungan langsung yang saling mempengaruhi antara $\boldsymbol{T}$ dan $\boldsymbol{A}$. Saling pengaruh antara keduanya baru akan terjadi apabila terjadi perubahan salah satu antara $\boldsymbol{T}$ atau $\boldsymbol{A}$ yang dapat mengakibatkan perubahan pada pola $\boldsymbol{F}$, yang terus akan saling menuju kepada suatu kondisi keseimbangan dan setiap saat akan saling mempengaruhi.

Kegiatan transportasi suatu daerah erat kaitannya dengan keadaan sosio ekonomi daerah tersebut.Untuk lebih memahami dan mendapatkan alternatif pemecahan masalah yang terbaik, perlu dilakukan pendekatan secara sistem.Sistem transportasi dijelaskan dalam bentuk sistem transportasi makro yang terdiri dari beberapa sistem transportasi mikro yang masing-masing saling terkait dan saling mempengaruhi [4].

Sistem transportasi tersebut terdiri atas:(i) Sistem Kegiatan (Transport Demand); (ii) Sistem Jaringan Prasarana Transportasi (Transport Supply); (iii) Sistem Pergerakan Lalulintas (Traffic); dan (iv) Sistem Kelembagaan (Institution).Interaksi sistem kegiatan dan sistem jaringan transportasi akan menghasilkan suatu pergerakan manusia dan/atau barang dalam bentuk pergerakan kendaraan dan/atau orang (pejalan kaki atau pedestrian).Sistem kegiatan, sistem jaringan dan sistem pergerakan saling mempengaruhi satu sama lain. Perubahan pada sistem kegiatan akan mempengaruhi sistem jaringan melalui suatu perubahan pada tingkat pelayanan pada sistem pergerakan. Begitu juga perubahan pada sistem jaringan dapat mempengaruhi sistem kegiatan melalui peningkatan mobilitas dan aksesibilitas dari sistem pergerakan tersebut.

Transportasi darat adalah pengangkutan penumpang dan barang dengan menggunakan kendaraan, yaitu sarana transportasi selain makhluk hidup berupa mobil, motor, dan kereta. Transportasi darat meliputi transportasi jalan, jalan rel, angkutan sungai, danau dan penyeberangan. Prasarana transportasi daratberupa jalan, jembatan, rel, terminal, dan stasiun.

Jaringan transportasi jalan adalah serangkaian simpul dan atau ruang kegiatan yang dihubungkan oleh ruang lalu lintas sehingga membentuk satu kesatuan sistem jaringan untuk keperluan penyelenggaraan lalu lintas dan angkutan jalan.

Logistik adalah proses merencanakan, menerapkan, dan mengendalikan aliran dan penyimpanan produk, jasa, dan informasi terkait dari titik asal ke titik konsumsi dengan efektif dan efisien, dan bertujuan memenuhi kebutuhan pelanggan [5]. Logistik meliputi perencanaan dan pengendalian aliran material dan informasi antar organisasi, baik pada sektor publik maupun swasta [6]. Terdapat lima area yang terintegrasi menjadi suatu sistem logistik, yaitu (i) order processing; (ii) inventori; (iii) transportasi; (iv) pergudangan, (v) serta material handling, pengemasan, dan fasilitas jaringan [7]. Kelima area tersebut saling berinteraksi satu sama lain, seperti dapat dilihat pada Gambar 4 di bawah ini.

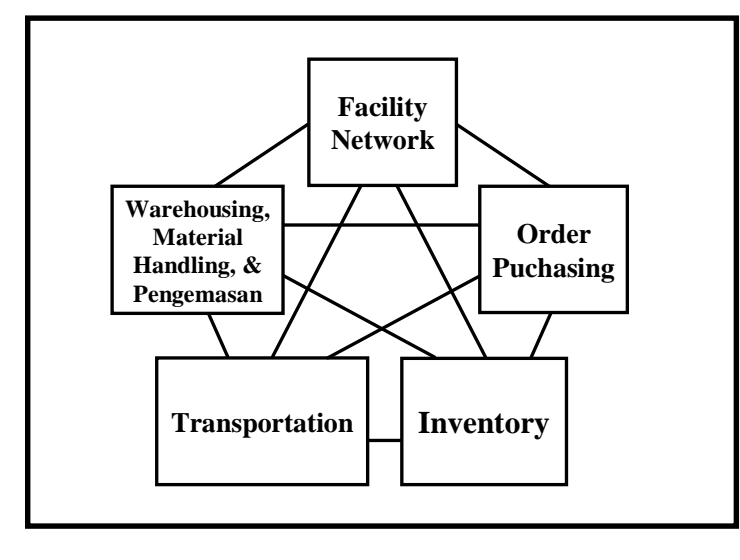

Gambar 4. Logistik terintegrasi

Misi dari sistem logistik adalah memberikan barang yang tepat (the right goods) di tempat yang 
tepat(in the right place)pada waktu yang tepat(at the right time) dengan mengoptimalkan performansi (misalnya minimasi total biaya operasional) dan memenuhi sejumlah batasan (misalnya batasan anggaran dana) [6].

Dengan mempertimbangkan data-data di atas, maka ada beberapa kesimpulan pokok tentang latar belakang dari pentingnya penelitian ini, yaitu:

- Dari sisi kebijakan pemerintah terkait, KEK Sei Mangkei mempunyai dasar dan potensi yang cukup kuat untuk ditindak-lanjuti;

- Dari sisi operasi sistem usaha (bisnis), sudah ada beberapa BUMN yang dibentuk dan/atau terlibat dalam rencana pengembangan KEK Sei Mangkei ke depan;

- Infrastruktur transportasi dan logistik sudah mulai dibangun dan memiliki prospek yang bagus untuk terus dikembangkan di masa mendatang;

- Aksesibilitas Pelabuhan Kuala Tanjung sangat penting dalam mendukung kelancaran arus barang di KEK Sei Mangkei.

Dengan demikian, perlu dipelajari tentang potensi pengembangan aksesibilitas antara Pelabuhan Kuala Tanjung dan KEK Sei Mangkei di masa mendatang.

\section{METODOLOGI PENELITIAN}

Metodologi penelitian yang diusulkan dalam penelitian ini adalah metodologi dengan kerangka berpikir sistem dimana KEK Sei MangkeiPelabuhan Kuala Tanjung diperlakukan sebagai suatu sistem rantai pasok yang berkelanjutan (sustainable supply chain) dengan tujuan utama pertumbuhan ekonomi dan pemerataan, seperti yang diperlihatkan pada Gambar 5 di bawah ini.

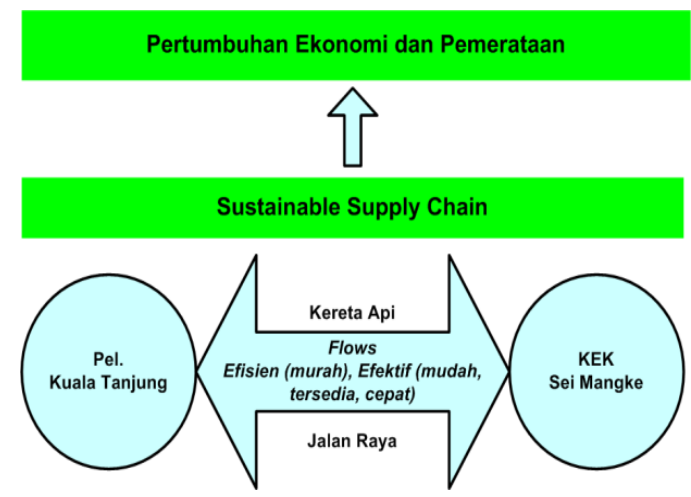

Gambar 5. Kerangka berpikir sistem.

Kerangka berpikir tersebut juga sesuai dengan pemikiran dari Direktur Jenderal Pengembangan Perwilayahan Industri Kementerian Perindustrian yang mengusulkan integrasi dan interkonektivitas infrastruktur dasar dan logistik KEK Sei Mangkei
[1], seperti yang diperlihatkan pada Gambar 6 di bawah ini.

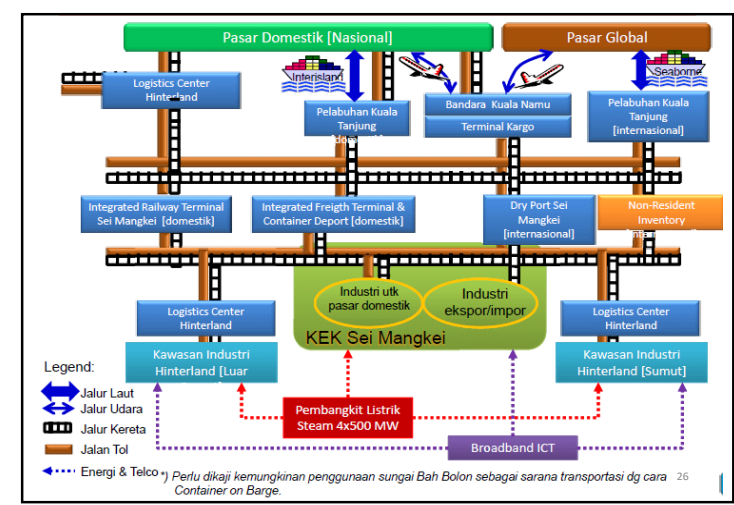

Gambar 6. Integrasi dan interkonektivitas infrastruktur dasar dan logistik KEK Sei Mangkei.

Substansi analisis dalam penelitian ini akan mencakup: (i) Analisis sistem industri, perdagangan (ekspor-impor), transportasi, distribusi, dan logistik di KEK Sei MangkeiPelabuhan Kuala Tanjung; (ii) Analisis kebijakankebijakan pemerintah terkait dengan pengembangan KEK Sei Mangkei-Pelabuhan Kuala Tanjung; (iii) Analisis pelaku bisnis dan rencana pengembangan bisnis, khususnya di KEK Sei Mangkei; (iv) Analisis konektivitas dan aksesibilitas KEK Sei Mangkei-Pelabuhan Kuala Tanjung; dan (v) Analisis dampak yang muncul dari beroperasinya sistem rantai pasok KEK Sei Mangkei-Pelabuhan Kuala Tanjung.

Model yang dijadikan acuan dalam pengukuran dan pengembangan aksesibilitas, di mana aksesibilitas dipengaruhi oleh enam faktor, yaitu spasial atau ruang, fisik, waktu, keuangan, lingkungan, dan informasi [8]. Indikator yang dapat digunakan untuk mengukur aksesibilitas tersebut disajikan pada Gambar 8 di bawah ini.

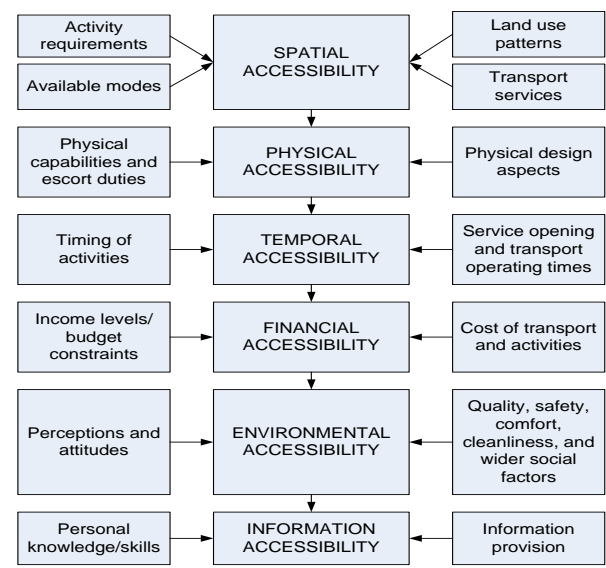

Gambar 7. Model pengukuran aksesibilitas.

III. HASIL PENELITIAN 


\section{A. Aksesibilitas KEK Sei Mangkei-Pelabuhan Kuala Tanjung.}

Aksesibilitas Pelabuhan Kuala Tanjung dalam mendukung KEK Sei Mangkei akan difokuskan pada integrasi transportasi untuk tiga tahap, yaitu jangka pendek (2016-2020), jangka menengah (2021-2025), dan jangka panjang (2026-2030) berdasarkan prediksi data bangkitan di KEK Sei Mangkei sampai dengan tahun 2030. Tabel I menyajikan prediksi bangkitan di KEK Sei Mangkei yang ditambah dengan $20 \%$ yang merupakan prediksi bangkitan yang muncul dari wilayah sekitarnya, prediksi bangkitan ini memakai perhitungan hasil dari traffic counting sebagai data primer dan data dari kementerian perhubungan sebagai data sekunder.

TABEL I

PREDIKSI BANGKITAN ANGKUTAN BARANG SEI MANGKEI

\begin{tabular}{|c|c|c|c|}
\hline Tahun & $\begin{array}{l}\text { Volume di } \\
\text { KEK } \\
\text { Sei } \\
\text { Mangkei } \\
\text { (juta ton) } \\
\end{array}$ & $\begin{array}{c}\text { Kebutuhan } \\
\text { dari } \\
\text { luar kawasan } \\
20 \% \\
\text { (juta ton) } \\
\end{array}$ & $\begin{array}{c}\text { Volume } \\
\text { total } \\
\text { (juta ton) }\end{array}$ \\
\hline 2016 & 1.605 & 0.321 & 1.926 \\
\hline 2017 & 1.705 & 0.341 & 2.046 \\
\hline 2018 & 1.805 & 0.361 & 2.166 \\
\hline 2019 & 1.905 & 0.381 & 2.286 \\
\hline 2020 & 2.005 & 0.401 & 2.406 \\
\hline 2021 & 2.105 & 0.421 & 2.526 \\
\hline 2022 & 2.205 & 0.441 & 2.646 \\
\hline 2023 & 2.205 & 0.441 & 2.646 \\
\hline 2024 & 2.205 & 0.441 & 2.646 \\
\hline 2025 & 2.505 & 0.501 & 3.006 \\
\hline 2026 & 2.505 & 0.501 & 3.006 \\
\hline 2027 & 2.805 & 0.561 & 3.366 \\
\hline 2028 & 2.805 & 0.561 & 3.366 \\
\hline 2029 & 2.805 & 0.561 & 3.366 \\
\hline 2030 & 2.805 & 0.561 & 3.366 \\
\hline
\end{tabular}

Adapun jalan akses KEK Sei Mangkei dan jalan akses Kuala Tanjung dapat dilihat pada Gambar 9 dan Gambar 10

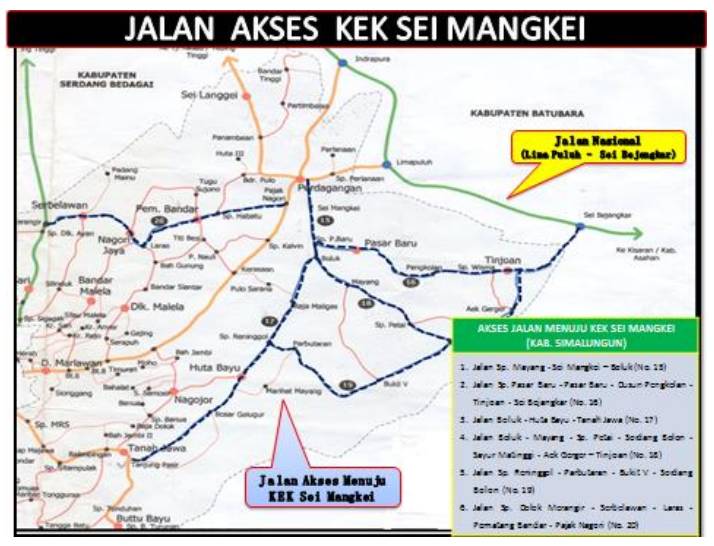

Gambar 9. Jalan akses KEK Sei Mangkei.

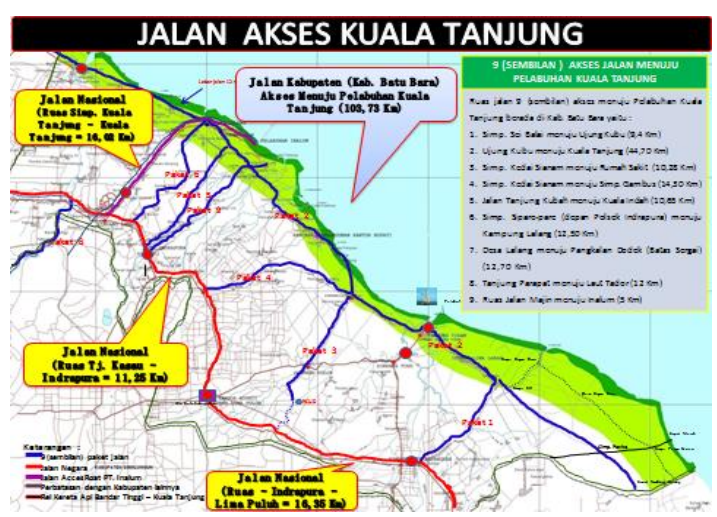

Gambar 10. Jalan Akses Kuala Tanjung.

Jaringan Jalan Kereta dari Sei MangkeiPelabuhan Belawan, dan Sei Mangkei-Pelabuhan Kuala Tanjung ditunjukan pada gambar 11 .

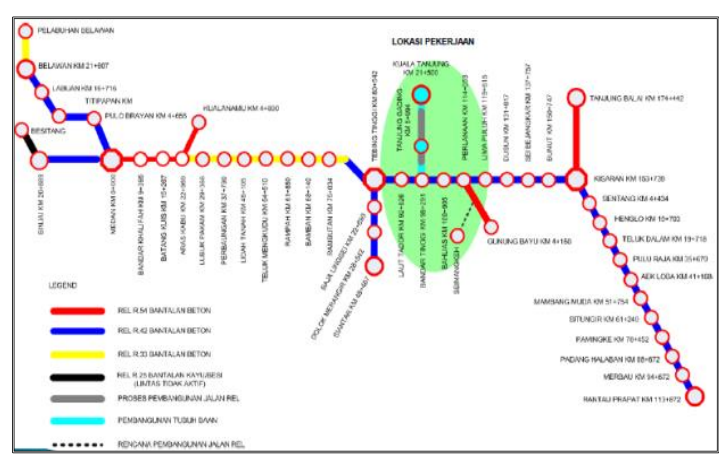

Gambar 11. Jaringan Jalan Kereta yang ada serta trase baru dari Sei Mangkei - Pelabuhan Kuala Tanjung

Berdasarkan perhitungan kapasitas lintas di atas, bahwa tanpa adanya penambahan stasiun baru maka sisa kapasitas lintas $16 \mathrm{KA}$, atau $8 \mathrm{KA}$ pulang pergi. Untuk menghitung daya muat lintas Sei Mangkei-Belawan perlu asumsi perhitungan.

Pola operasi kereta api barang dapat dilihat pada Gambar 12. 


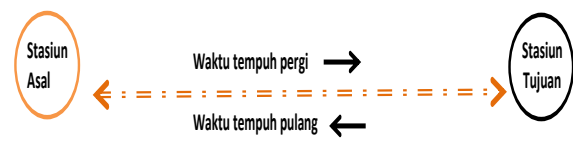

Gambar 12. Pola operasi kereta api barang.

Persamaan waktu siklus KA dapat dilihat pada rumus (1).

$\mathrm{T}_{\text {siklus }}=\left(\mathrm{T}_{\mathrm{b} / \mathrm{m}}+\mathrm{T}_{\mathrm{p}}+\mathrm{T}_{\mathrm{l}}+\mathrm{T}_{\mathrm{ps}}+\mathrm{T}\right) \times 2$

dimana :

$\mathrm{T}_{\text {siklus }}=$ waktu siklus $\mathrm{KA}$

$\mathrm{T}_{\mathrm{b} / \mathrm{m}}=$ waktu bongkar/muat

$\mathrm{T}_{\mathrm{p}} \quad$ = waktu persiapan

$\mathrm{T}_{1} \quad$ = waktu langsir

$\mathrm{T}_{\mathrm{ps}}=$ waktu persilangan

$\mathrm{T} \quad$ = waktu perjalan

Perhitungan Waktu Siklus dan Kapasitas Muat dengan jumlah pemberangkatan KA berdasarkan sisa kapasitas terkecil, yaitu $16 \mathrm{KA}$ atau $8 \mathrm{KA}$ (pulang dan pergi) hasilnya ditunjukan pada Tabel II dan Tabel III.

TABEL II

ASUMSI DAN HASIL PERHITUNGAN KAPASITAS MUAT KA

\begin{tabular}{|c|c|c|c|c|}
\hline \multicolumn{2}{|c|}{ Daya Tarik lokomotif (ton) } & \multicolumn{2}{|c|}{ Daya Tarik 2 Lokomotif (ton) } & Unit \\
\hline CC 201 & CC 201 & CC 201 & CC 201 & \\
\hline$V=30$ & $V=40$ & $V=30$ & $\mathrm{~V}=40$ & \\
\hline 687 & 475 & 1168 & 808 & Ton \\
\hline \multicolumn{5}{|c|}{ Asumsi Berat Kontainer dan muatan 25 ton } \\
\hline \multicolumn{5}{|c|}{\begin{tabular}{|l|l}
1 gerbong $=41$ ton (Gerbong kosong $(16)+$ Muatan $(25)$ ) &
\end{tabular}} \\
\hline 17 & 12 & 28 & 20 & Gerbong/KA \\
\hline \multicolumn{5}{|c|}{2 Teus/Gerbong $=25$ ton/gerbong } \\
\hline 34 Teus/KA & 24 Teus/KA & 56 Teus & 40 Teus & Teus/KA \\
\hline 425 & 300 & 700 & 500 & Ton / rangkaian KA \\
\hline \multicolumn{5}{|c|}{ Jarak Sei Mangkei - Belawan $=140 \mathrm{~km}$} \\
\hline \multicolumn{5}{|c|}{$\begin{array}{l}\text { Jarak Sei Mangkei - Pelabuhan Kuala Tanjung } \\
\qquad 119.483-98.291=42.692 \mathrm{~km}=43 \mathrm{~km}\end{array}$} \\
\hline \multicolumn{5}{|c|}{$\begin{array}{c}\text { Catatan : } 1 \text { tahun } 340 \text { hari kerja, frekwensi : } 8 \mathrm{KA} / \text { hari untuk ke Belawan, karena sisa } \\
\text { kapasitas Batangkuis - Bandar Khalifah paling kecil (16) }\end{array}$} \\
\hline $\begin{array}{l}\text { Kapasitas angkut } \\
\text { ke Belawan } \\
\text { (Ton/tahun) }\end{array}$ & 816,000 & $\begin{array}{c}\text { Jika } \\
\text { Menggunakan } \\
20 \text { Gerbong/ } \\
\text { rangkaian KA }\end{array}$ & $1,360,000$ & Ton/tahun \\
\hline $\begin{array}{r}\text { Kapasitas angkut } \\
\text { ke Belawan (Teus) }\end{array}$ & 65,280 & $\begin{array}{l}\text { maka } \\
\text { kapasitas }\end{array}$ & 108,800 & Teus/Tahun \\
\hline
\end{tabular}

TABEL III

PERHITUNGAN WAKTU SIKLUS DAN KAPASITAS MUAT KA PER TAHUN

\begin{tabular}{|c|c|c|}
\hline Waktu Langsir & 10 & Menit \\
\hline $\begin{array}{l}\text { Waktu Bongkar/ } \\
\text { muat /Teus }\end{array}$ & 4 & Menit \\
\hline $\begin{array}{l}\text { Waktu Pemeriksaan } \\
\text { Persiapan }\end{array}$ & 15 & Menit \\
\hline $\begin{array}{l}\text { Jarak Sei-mangkei - } \\
\text { Belawan }\end{array}$ & 140 & $\mathrm{Km}$ \\
\hline Kecepatan Operasi & 40 & $\mathrm{Km}$ \\
\hline $\begin{array}{l}\text { Waktu persilangan/ } \\
\text { penyusulan }\end{array}$ & 30 & Menit \\
\hline $\begin{array}{l}\text { Waktu tempuh } \\
\text { pergi/pulang }\end{array}$ & 210 & Menit \\
\hline Waktu Langsir & 10 & Menit \\
\hline $\begin{array}{l}\text { Waktu Bongkar/ } \\
\text { muat /Teus }\end{array}$ & 4 & Menit \\
\hline $\begin{array}{l}\text { Waktu Pemeriksaan } \\
\text { Persiapan }\end{array}$ & 15 & Menit \\
\hline & & Menit \\
\hline Waktu siklus KA & 715 & Menit \\
\hline Frekwensi/hari/KA & 2 & \\
\hline Volume Terangkut & 600 & ton/hari \\
\hline $\begin{array}{l}\text { Kapasitas angkut/ } \\
\text { tahun/KA }\end{array}$ & $1,632,000$ & Ton/tahun \\
\hline $\begin{array}{l}\text { Kapasitas angkut } \\
\text { Tersedia/ tahun }\end{array}$ & 130,560 & Teus/tahun \\
\hline
\end{tabular}

Pembangunan jalan akses rel KA dari KEK Sei Mangkei ke Lintas Gunung Bayu Perlanaan jika telah selesai, maka barang hasil produksi atau bahan pendukung dapat diangkut dengan menggunakan Kereta Api dari dan menuju Pelabuhan Belawan ke/dari KEK Sei Mangkei.

Data sarana yang dimiliki oleh PT KAI Divre I Sumatera Utara saat ini ditunjukan pada Tabel IV di bawah ini.

TABEL IV

LOKOMOTIF, KERETA, DAN GERBONG DI DIVRE I SUMATERA UTARA

\begin{tabular}{|c|c|c|}
\hline $\mathbf{N}$ & Jenis Sarana & Jumlah \\
\hline 1 & $\begin{array}{lr}\text { Lokomotif } & \text { CC } \\
& 2 \\
& 0 \\
& 1 \\
\end{array}$ & 8 \\
\hline 2 & \begin{tabular}{lr} 
Lokomotif & \multicolumn{1}{c}{ BB } \\
& 3 \\
& 0 \\
& 2
\end{tabular} & 7 \\
\hline 3 & $\begin{array}{lr}\text { Lokomotif } & \text { BB } \\
& 3 \\
& 0 \\
& 3 \\
\end{array}$ & 13 \\
\hline 4 & \begin{tabular}{lr} 
Lokomotif & \multicolumn{1}{c}{ BB } \\
& 3 \\
& 0 \\
& 6 \\
\end{tabular} & 9 \\
\hline 5 & $\begin{array}{lr}\text { Lokomotif } & \text { BB } \\
& 2 \\
& 0 \\
& 3 \\
\end{array}$ & 6 \\
\hline \multicolumn{2}{|c|}{ Jumlah lokomotif } & 43 \\
\hline 1 & Kereta K1 & 7 \\
\hline 2 & Kereta K2 & 23 \\
\hline 3 & Kereta K3 & 22 \\
\hline 4 & Kereta KMP2 & 4 \\
\hline 5 & Kereta KP2 & 2 \\
\hline 6 & Kereta KMP3 & 2 \\
\hline 7 & Kereta P & 2 \\
\hline 8 & Kereta B & 8 \\
\hline \multicolumn{2}{|c|}{ Jumlah kereta } & 70 \\
\hline 1 & Gerbong GK & 273 \\
\hline 2 & Gerbong GT & 39 \\
\hline 3 & Gerbong GD & 88 \\
\hline 4 & Gerbong GB & 24 \\
\hline 5 & Gerbong SN & 3 \\
\hline \multicolumn{2}{|c|}{ Jumlah gerbong } & 427 \\
\hline
\end{tabular}

Menurut informasi dari Balai Teknik Perkeretaapian Sumatera Utara, panjang rangkaian kereta api, termasuk 1 lokomotif, untuk angkutan barang curah cair dengan gerbong ketelan (tangki) adalah 140 meter (10 gerbong). Angkutan barang non cair dengan gerbong datar sepanjang 193,2 meter (12 gerbong), sehingga tidak perlu mengubah atau memperpanjang emplasemen stasiun eksisting (panjang sepur terpendek 239 meter).

Pada saat itu diharapkan jalur rel kereta api dari KEK Sei Mangkei ke Pelabuhan Kuala Tanjung 
Jurnal Media

Teknik dan

Sistem Industri

sudah terhubung dan didukung dengan beroperasinya Terminal Multipurpose di Pelabuhan Kuala Tanjung. Dengan demikian, semua bangkitan di KEK Sei Mangkei akan dikirimkan ke Pelabuhan Kuala Tanjung, baik melalui kereta api dan/atau truk, sedangkan Pelabuhan Belawan akan menjadi cadangan (back up) pada saat Pelabuhan Kuala Tanjung tidak dapat beroperasi dengan optimal. Untuk menghitung kapasitas angkut kereta api perlu diketahui panjang jarak dari Stasiun KEK Sei Mangkei ke Stasiun di Pelabuhan Kuala Tanjung seperti yang disajikan pada Tabel V di bawah ini.

TABEL V

PANJANG LinTASAN KEK SEI MANGKEI - PElabUhan KuAla TANJUNG.

\begin{tabular}{|c|c|}
\hline Lintas & Jarak (km) \\
\hline Stasiun KEK Sei Mangkei - Stasiun Perlanaan & 4,95 \\
\hline Stasiun Perlanaan - Stasiun Bahlias & 4,20 \\
\hline Stasiun Bahlias - Stasiun Bandar Tinggi & 11,60 \\
\hline Stasiun Bandar Tinggi - Stasiun Tanjung Gading & 6,00 \\
\hline Stasiun Tanjung Gading - Stasiun Kuala Tanjung & 13,50 \\
\hline Stasiun Kuala Tanjung - Stasiun Pel.Kuala Tanjung & 2,00 \\
\hline Jumlah & 42,35 \\
\hline
\end{tabular}

Untuk lintas Sei Mangkei-Pelabuhan Kuala Tanjung, maka gradien penentu besarnya $2 \%$, sehingga daya tarik lokomotif CC 201 mencapai 1041.5 ton pada kecepatan $45 \mathrm{~km} / \mathrm{jam}$ atau 881 ton pada kecepatan $50 \mathrm{~km} / \mathrm{jam}$. Hal ini mengakibatkan kemampuan tarik gerbong menjadi lebih dari 20 gerbong/rangkaian. Hasil perhitungan kapasitas muat dapat dilihat pada tabel VI di bawah ini.

TABEL VI

HASIL PERHITUNGAN KAPASITAS MUAT SEI MANGKEI KUALA TANJUNG.

\begin{tabular}{|c|c|c|}
\hline ya Tarik 1 Lokomotif $\mathrm{CC} 201$ pada $\mathrm{V}=50=8$ & & Keterangan \\
\hline Gerbong yang dipakai & 20 & unit \\
\hline Jarak Sei Mangkei - Kuala Tanjung & 43 & $\mathrm{~km}$ \\
\hline $\begin{array}{c}\text { Waktu tempuh Sei Mangkei-Kuala Tanjung } \\
\text { dengan } \mathrm{V}=50 \mathrm{~km} / \mathrm{jam}=\end{array}$ & 57 & \\
\hline Waktu Bongkar/muat/KA & 160 & menit/gerbong \\
\hline Waktu Langsir & 15 & menit/KA \\
\hline Waktu Persiapan dan Pemeriksaan rem & 15 & menit \\
\hline Waktu tempuh Kembali dari Kuala Tanjung & 57 & menit \\
\hline $\begin{array}{c}\text { Waktu Persilangan/Penyusulan } \\
\end{array}$ & 15 & menit \\
\hline Waktu siklus/KA & 525 & \\
\hline Jumlah Rit/hari & & $(6 \mathrm{KA})$ \\
\hline Total Muatan/hari/KA & 1372 & ton \\
\hline Waktu kerja/tahun & 340 & Hari \\
\hline & 466,582 & ton \\
\hline $\begin{array}{c}\text { Total Muatan/tahun/KA } \\
\text { Kapasitas Frekwensi KA Sei Mangkei - Kuala } \\
\text { Tanjung } 86 \text { KA atau }\end{array}$ & 43 & Pulang-pergi \\
\hline $\begin{array}{l}\text { Kapasitas maksimum Sei Mangkei - Kuala } \\
\text { Tanjung }\end{array}$ & $20,063,024$ & ton/tahun \\
\hline Kebutuhan Angkutan sampai 2030 & $3,366,000$ & ton/tahun \\
\hline Jika dilayani KA $100 \%$ maka dibutuhkan $=$ & & KA \\
\hline Jika Siap Guna Operasi & $90 \%$ & \\
\hline Jumlah Gerbong dibutuhkan & 178 & Gerbong Datar \\
\hline Jumlah Lok CC201 dengan cadangan & & \\
\hline
\end{tabular}

TABEL VII

ANALISIS ANGKUTAN KERETA API

\begin{tabular}{|c|c|}
\hline Pola Operasi & $\begin{array}{c}1 \text { Lokomotif CC 201 dan } \\
12 \text { gerbong PPCW }\end{array}$ \\
\hline
\end{tabular}

\begin{tabular}{|c|c|}
\hline $\begin{array}{l}\text { Jarak KEK Sei Mangkei } \\
\text { - Pel. Kuala Tanjung }\end{array}$ & $42,45 \mathrm{~km}$ \\
\hline Kecepatan Operasi & $45 \mathrm{~km} / \mathrm{jam}$ \\
\hline Waktu Perjalanan & 57 \\
\hline Waktu langsir & 10 menit \\
\hline $\begin{array}{l}\text { Waktu } \\
\text { Persiapan/Pemeriksaan }\end{array}$ & 15 \\
\hline Waktu persilangan & 30 menit \\
\hline Waktu bongkar/muat & $\begin{array}{l}4 \text { menit/gerbong atau } 96 \\
\text { menit untuk } 1 \text { rangkaian } \\
\text { (muat dan bongkar) }\end{array}$ \\
\hline Waktu siklus & $\begin{array}{l}2 *(57+10+15+96+30)=416 \\
\text { menit }\end{array}$ \\
\hline Rit/hari & 3,5 \\
\hline Kapasitas angkut/gerbong & 25 ton \\
\hline Kapasitas angkut/hari & $12 * 25 * 3.5=1050$ ton/hari \\
\hline Kapasitas/tahun & $\begin{array}{l}340 * 1050=357.000 \\
\text { ton/tahun }\end{array}$ \\
\hline $\begin{array}{l}\text { Jumlah Lokomotif CC } \\
201\end{array}$ & 8 unit \\
\hline Jumlah hari kerja/tahun & 340 hari \\
\hline Kapasitas angkut/tahun & $357.000 * 8=2.856 .000$ \\
\hline $\begin{array}{l}\text { Prediksi muatan tahun } \\
2017\end{array}$ & 2.046 .000 ton \\
\hline $\begin{array}{l}\text { Prediksi sampai tahun } \\
2024\end{array}$ & 2.646 .000 ton \\
\hline $\begin{array}{l}\text { Jumlah gerbong yang } \\
\text { dibutuhkan }\end{array}$ & $=(8 * 12) / 90 \%=107$ unit \\
\hline
\end{tabular}

\section{PEMBAHASAN}

Kawasan pelabuhan Kuala Tanjung mempunyai akses jalan utama ke ruas jalan nasional Lintas Timur Sumatera yang kondisi lebar jalan di atas 10 meter. Status jalannya adalah bekas kawasan industri Inalum-Asahan. Namun akses jalan lainnya adalah jalan kabupaten dengan fungsi jalan yang rendah dan lebar jalan yang terbatas. Di dalam dokumen-dokumen rencana tata ruang yang telah dikemukakan sebelumnya, akses jaringan jalan ke kedua kawasan akan ditingkatkan kelasnya guna mendukung pergerakan terutama angkutan barang/industri. Selain itu, angkutan barang ke dan dari kedua kawasan akan didukung oleh jaringan kereta api. Dukungan lain adalah adanya rencana jalan tol yang memiliki exit/entry mendekati KEK Sei Mangkei dan kawasan pelabuhan Kuala Tanjung. Dengan demikian dapat disimpulkan bahwa semua rencana tata ruang yang 
telah ditetapkan maupun yang masih berupa rancangan telah mendukung peningkatan konektivitas dan aksesibilitas KEK Sei Mangkei dan kawasan pelabuhan Kuala Tanjung, baik dari daerah belakangnya/hinterland, maupun ke daerah tujuan pemasaran produknya.

Pola operasi kereta barang, dimulai dari stasiun asal Sei Mangkei, Kereta melakukan langsiran untuk menyiapkan gerbong yang akan dimuat barang dalam bentuk kontainer pada rel muat. Pemuatan barang dilakukan sesuai dengan panjangnya rangkaian atau banyaknya gerbong yang akan dimuat. Setelah selesai langsir, maka dilakukan proses pemuatan dengan menggunakan container loader sampai selesai, kemudian kereta api dipersiapkan dan dokumen-dokumen yang diperlukan untuk dibawa oleh masinis atau awak kereta api. Lalu pemeriksaan Kereta, dan pengecekan rem setelah siap, maka kereta api diberangkatkan sesuai dengan jadwalnya, jika dalam perjalanan ternyata ada informasi persilangan, maka kereta dengan prioritas lebih rendah berhenti di stasiun yang memiliki emplasemen yang cukup untuk penyusulan atau persilangan. Setelah sampai di Stasiun Tujuan, maka selanjutnya kereta api dibongkar dan dimuat kontainer baru yang akan ditransport ke Sei Mangkei, dan proses diatas dilakukan kembali, sampai kereta api bisa kembali ke stasiun Sei Mangkei. Kereta api mengalami 2 (dua) kali muat dan 2 (dua) kali bongkar.

Dari Hasil Perhitungan pada Tabel III terlihat bahwa tanpa melakukan pembangunan stasiun baru, kapasitas muat lintas Sei Mangkei-Belawan adalah 1.632.000 ton, sedangkan kebutuhan adalah 2.046.000 ton sehingga sisa muatannya adalah $414.000 / 340=1.217 .65$ ton. Kapasitas angkut/truk/hari adalah 50 ton. Jadi truk yang dibutuhkan adalah 25 truk dengan head way 57,6 menit. Bila kebijakan angkutan ditetapkan $100 \%$ pada kereta api, maka jumlah gerbong yang dibutuhkan/rangkaian KA adalah = 16 gerbong, dengan daya angkut 2.176 .000 ton dan jika menggunakan 1 lokomotif maka kecepatan operasi harus diturunkan menjadi $32 \mathrm{~km} / \mathrm{jam}$.

Berdasarkan Tabel VI, mendukung kemampuan pemenuhan kapasitas KA, maka pihak pengelola infrastruktur jalan rel harus memperpanjang emplasemen di stasiun yang memungkinkan terjadinya persilangan. Selain itu, saat ini hanya ada gerbong datar sebanyak 88 sehingga diperlukan pengadaan gerbong datar sebanyak 178 dikurangi dengan sisa gerbong yang ada. Tapi bila tidak dilakukan perbaikan emplasemen, maka akan terjadi satu rangkaian KA hanya 12 gerbong. Untuk perhitungannya dapat diilustrasikan pada Tabel VII.

Berdasarkan Kondisi perhitungan Tabel VII maka dengan memiliki 8 (delapan) lokomotif CC 201, PT KAI mampu melakukan pengangkutan sampai tahun 2025, dengan catatan jumlah gerbong datar di tambah. Hasil perhitungan diatas, memberikan informasi bahwa jika kereta api beroperasi dengan kondisi pola operasi atau stam formasi seperti sekarang serta emplasemen yang hanya mampu menampung 12 gerbong, maka peran kedua moda truk dan kereta api akan dibutuhkan untuk mengangkut muatan dari KEK Sei Mangkei ke Pelabuhan Kuala Tanjung. Jika kapasitas angkut kereta api tidak ditingkatkan sampai dengan tahun 2030 akan makin banyak jumlah truk yang dibutuhkan dan hal ini akan berimplikasi kepada headway yang makin pendek dan juga akan menambah volume lalu lintas di jalan

\section{KESIMPULAN}

Berdasarkan hasil penelitian ini maka dapat disimpulkan bahawa aksesibilitas Pelabuhan Kuala Tanjung akan meningkat seiring dengan rencana pembangunan akses ruas jalan, angkutan barang dengan truk dari KEK Sei Mangkei ke Pelabuhan Belawan dengan menggunakan jalan raya akan menghadapi kemacetan yang berdampak pada lamanya waktu tempuh karena kondisi jalan yang dilalui adalah jalan trans Sumatera lintas Timur dimana jalan kabupaten/kota klasnya tidak sama dengan jalan nasional, demikian juga lebar jalan yang tidak seragam dari $5 \mathrm{~m}$ sampai dengan 7 meter. Hambatan terberat adalah kepadatan lalu lintas yang cukup tinggi terutama memasuki wilayah Medan ditempuh dengan kondisi padat merayap, sehingga dari Sei Mangkei ke Belawan ditempuh hampir 14 jam, padahal jaraknya hanya $145-160 \mathrm{~km}$ atau rata-rata kecepatan operasi hanya $10-20 \mathrm{~km} / \mathrm{jam}$.

Mulai tahun 2021 dengan telah siap beroperasinya Terminal Petikemas di Pelabuhan Kuala Tanjung, maka seluruh bangkitan barang dari KEK Sei Mangkei sampai dengan tahun 2030 dapat dilayani di Pelabuhan Kuala Tanjung dengan menggunakan moda kereta api dan truk yang dilayani di Terminal Petikemas dan Terminal Multipurpose, sehingga Pelabuhan Belawan dapat menjadi cadangan pada saat ada gangguan di Pelabuhan Kuala Tanjung. Manajemen dan rekayasa laluintas akan diperlukan dalam mengatur potensi kemacetan yang disebabkan oleh perlintasan sebidang antara jalan raya dan rel kereta api serta dengan jumlah truk yang akan digunakan untuk mengangkut muatan dari KEK 
Sei Mangkei ke Pelabuhan Belawan dan dari KEK Sei Mangkei ke Pelabuhan Kuala Tanjung.

\section{REFERENSI}

[1] Direktur Jenderal Pengembangan Perwilayahan Industri "Percepatan Pembangunan Kawasan Industri di Luar Pulau Jawa Melalui Pembangunan Infrastruktur Pendukung dalam Kerangka MP3EI”, Jakarta, 2013.

[2] Morlok, K. Edward. (1978). Introduction To Transportation Engineering And Planning, McGrawHills, Inc.

[3] Manheim Marvin L. (1979), Fundamentals of Transportation Systems Analysis. Volume 1: Basic Concepts, The MIT Press, Cambridge

[4] Tamin, Ofyar, Z. (2008), "Perencanaan, Pemodelan, dan Rekayasa Transportasi: Teori, Contoh Soal, dan Aplikasi", Penerbit ITB, 2008.

[5] Coyle, John C., Edward J. Bardi, \&C. John Langley Jr. (2003). The Management of Business Logistics. Canada : Thomson South-Western

[6] Ghiani, Gianpaolo, Gilbert Laporte, \& Roberto Musmanno. (2004). Introduction to Logistic Systems Planningand Control. West Sussex, England: John Wiley \& Sons Ltd.

[7] Bowersox, Donald J., David J. Closs, \& M. Bixby Cooper. (2003). Supply Chain Logistics Management. New York :McGraw-Hill.

[8] Halden, D., Jones, P. And Wixey, S. (2005). Working Paper 3 Acccesibility Analysis Literature Review, Transport Studies Group, University of Westminster. 